\title{
Exercise-induced pulmonary haemorrhage in horses - review
}

\author{
Gabriel Morán ${ }^{1}$, Hugo Folch ${ }^{2}$ \\ Universidad Austral de Chile, ${ }^{1}$ Faculty of Veterinary Science, Department of Pharmacology, \\ ${ }^{2}$ Faculty of Medicine, Department of Immunology, Valdivia, Chile \\ Received November 27, 2012 \\ Accepted May 29, 2013
}

\begin{abstract}
Exercise-induced pulmonary haemorrhage is a major cause of poor performance in the equine athlete. It is an important cause of exercise intolerance and results from strenuous exercise and pathophysiological changes in the equine lung and possibly in the airways. Endoscopic surveys of the respiratory tracts of horses after competitive events have shown that many horses experience exercise-induced pulmonary haemorrhage. The reported incidence of exercise-induced pulmonary haemorrhage in different breeds varies between $40-85 \%$. The cause of bleeding in exercising horses has fostered considerable debate over the past three centuries, but currently, the most accepted hypothesis is that the source of haemorrhage is disruption of the pulmonary capillaries during exercise. Furosemide is the medication used most widely for the treatment and prevention of exercise-induced pulmonary haemorrhage. This review provides an update on the aetiology, clinical signs, physiopathology, diagnosis and treatment of exercise-induced pulmonary haemorrhage.
\end{abstract}

EIPH, pulmonary pressure, equine

The clinical signs of pulmonary bleeding after exercise in horses were first described by Markham (1688). Robertson (1913) reported the existence of epistaxis in racehorses, attributing it to a hyperaemic condition of the pulmonary vessels. Later, the epistaxis was attributed to an inherited condition in thoroughbred racehorses. Despite the time that has passed since the conditions of disease were first described, the cause of the disease and the optimal approach to treatment has not been established yet. According to Hinchcliff (2000), this phenomenon should not be considered a disease as such, but rather a common condition in sport horses. Other authors noted that bleeding after exercise is a physiological phenomenon related to extreme exercise, as the horse is genetically prepared for prolonged physical effort but with submaximal speed (West and Mathieu-Costello 1995). As stated by Derksen et al. (1992), the term that best describes this bleeding after athletic stress in horses is Exercise-Induced Pulmonary Haemorrhage (EIPH). This condition is defined as the presence of blood in the tracheobronchal circulation derived from the alveolar capillaries (Sweeney 1991). Its importance lies in the high incidence of this condition in sport horses; according to some authors, between 42 to $85 \%$ of horses that perform at high speeds suffer from it (Hillidge and Whitlock 1986; Birks et al. 2002, Newton and Wood 2002; Moran et al. 2003; Araya et al. 2007). Currently, the most accepted hypothesis regarding the origin and mechanism of EIPH involves the rupture of pulmonary capillaries during exercise (Poole et al. 2007).

\section{Predisposing factors for exercise-induced pulmonary haemorrhage}

Exercise-induced pulmonary haemorrhage does not have a single aetiologic factor such as race, sport, age, sex, environment or horse management, but it is supported by the coexistence of multiple predisposing factors (Art and Lekeux 1994). Many authors agree that the occurrence of EIPH is caused by effort, training or career (West et al. 1993). Horses subjected to high-speed sprinting that induces a heart rate of $240 / \mathrm{min}$ will suffer EIPH during the race or after it (Harkins et al. 1997). It is thought that the rate 
of acceleration of $17 \mathrm{~m} / \mathrm{s}$, which develops at the start of the race, causes an increase in pulmonary intravascular pressure and leads to EIPH (Erickson 1992). It has been found that pulmonary arterial pressure and venous pressure can reach $100 \mathrm{mmHg}$ and $80 \mathrm{mmHg}$ during peak exercise, respectively. Because pulmonary capillary pressure is in between the pulmonary arterial and venous pressure values, it has been estimated that pulmonary capillary pressure approaches $90-95 \mathrm{mmHg}$ during intense exercise (Langsetmo et al. 2000). These changes in pressure, accompanied by a negative pleural pressure and largevolume ventilation during maximal exercise may induce transmural capillary pressure that breaks the endothelial cell junctions in the alveolar epithelium, which ruptures the pulmonary capillaries (Manohar et al. 1993; West and Mathieu-Costello, 1994, 1995; Deksen et al. 2001). It has been shown that there is insufficient gas exchange due to the disruption of pulmonary capillaries, which suffer from arterial hypoxaemia and hypercapnia, which leads to increased anaerobic metabolism (Manohar et al. 2001; Caillaud et al. 2002). The fact that EIPH occurs after high-intensity exercise and prolonged low-intensity exercise suggests that this problem is due to extreme mechanical stresses on the tissue and pulmonary vessels during exercise (Art and Lekeux 1994). However, West et al. (1993) observed episodes of EIPH in horses just after walking and trotting. There is a trend related to age, where older horses have shown increased susceptibility to episodes of EIPH (Lapointe et al. 1994). Derksen (2009) suggested that increased prevalence of EIPH in older horses is due to progressive lung damage from repeated episodes of bleeding and the development of diseases of the upper airways. On the other hand, Oikawa (1999) showed that the equine lung is vulnerable to post-stress bleeding in individuals aged between 18 and 22 months. In addition, this part is vulnerable to trauma during exercise especially by the scapulo-humeral joint, where the forces are transmitted actively through the chest wall to reach the lung parenchyma (Newton et al. 2005). This may be because the scapula acts as a hinge to the spine, so that a portion of its surface moves toward the ribs plus some surrounding muscles may move medially (Schroter et al. 1998). Some authors have mentioned that the risk of developing EIPH cannot be readily determined from a combination of age, environment, race speed, race distance, track hardness or air quality (Hinchcliff et al. 2010).

\section{Possible causes of exercise-induced pulmonary haemorrhage}

The real causes of EIPH are still unknown. Numerous causes and pathophysiological mechanisms for the development of this disease have been proposed. These include infectious pulmonary diseases, which facilitate the development of fundamental EIPH by weakening the alveolar capillary walls and thus facilitating their rupture (McKane and Slocombe 2002), diseases of the lower airways, higher airway obstruction (Cook et al. 1988), blood hyperviscosity induced by exercise (Fedde and Wood 1993; Weiss and Smith 1998), mechanical stress associated with breathing and locomotion (Schroter et al. 1999), redistribution of blood flow in the lungs (Bernard et al. 1996, Erickson et al. 1999) and fluctuations in alveolar pressure and pulmonary hypertension (Pascoe 1997). Several of these factors can exert severe stress on the pulmonary system to the point that the capillaries fail. Obstruction of the upper and lower airways, which decreases pulmonary ventilatory capacity, would be one of the factors considered as important in the presentation of the disease (Cook et al. 1988). In this regard, Cook (2002) proposed that the dorsal displacement of the soft palate (DDSP) interrupts the flow of air into the lungs and therefore represents a major predisposing cause of EIPH. In an equine disease that manifests as DDSP upon exercise, the horse may appear normal when examined at rest. When exercise is initiated, displacement occurs suddenly, resulting in a reduction of speed or sudden arrest of the horse's movement. Some animals may even fall due to choking episodes, while others may experience fatal pulmonary bleeding. Moreover, trauma to the 
lung parenchyma, especially when it involves compression of the lung by the diaphragm that has been displaced by the abdominal contents, leads to temporary expansion of the alveoli during galloping. This trauma can destroy epithelial and endothelial cells (West and Mathieu-Costello 1994, 1995, 1998). The role of the diaphragm and other muscles in the horse's breathing has been widely discussed, particularly in relation to whether the action of the diaphragm is a passive or active movement acting against or in conjunction with the abdominal contents. It is likely that the pressure of the strap restricts movements of the chest wall and intensifies the dominance of the diaphragm as the driver of respiration. The relationship between the chest wall and abdominal and diaphragmatic movement is extremely complex but allows the apical and diaphragmatic lobes to be aired during lags in the exercise program (Schroter et al. 1998). Further, alterations in cardiac output predispose the horse to the presentation of EIPH. These alterations include a decrease in the diameter of the atrioventricular valves, the regurgitation of blood through the atrioventricular valves during ventricular systole, due to the high pressure associated with exercise and the slow rate of ventricular myocardial relaxation, which alters cardiac blood flow patterns (Langestmo et al. 1999). Pulmonary hypersensitivity reactions, especially recurrent airway obstruction (RAO), also play a role. These horses need 40\% more oxygen than a healthy horse, which results in inspiratory muscle fatigue, diminished availability of oxygen (Art et al. 1998). The body, in return, stimulates the formation of new pulmonary capillaries from the bronchial arteries, which are too fragile to withstand the pressure increases during exercise (Derksen et al. 1992; Newton and Wood 2002). In addition, some authors indicate that blood disorders alter pulmonary blood perfusion, which predisposes the animal to capillary rupture during exercise (Boucher 1989; Weiss et al. 1994; Caillaud et al. 2002).

\section{Pathophysiology of exercise-induced pulmonary haemorrhage}

Lung morphological studies have identified an anastomosis between the bronchial and pulmonary circulation in healthy horses. The neovascularization induced by inflammation and the large $\mathrm{vol} / \mathrm{min}$ heart ratio increase the pressure of the atrium and left ventricle, thus leading to an increase in pulmonary vascular pressure, which leads to capillary disruption and animal bleeds, which would explain the genesis of pulmonary haemorrhage (Pascoe 1997). Because we found inflammation and fibrosis of the airways in areas of pulmonary haemorrhage, it has been postulated that bronchiolitis may be the initial cause of EIPH. This theory suggests that bronchiolitis stimulates bronchial vascular proliferation and that these new vessels may rupture during exercise. Moreover, other authors showed that pulmonary inflammation and a decrease in the innate immune response mediated by alveolar macrophages could determine the presentation of EIPH (Michelotto et al. 2011). Bronchial neovascularization occurs during the natural course of healing. It is possible that once neovascularization has occurred, bronchial vessels may contribute to EIPH (McKane and Slocombe 2002). The pathophysiology of EIPH pathology is characterized by the occlusive remodelling of pulmonary veins. Affected veins have large collagen deposits in their walls which reduce the lumen size. In the caudodorsal regions, pulmonary vein wall remodeling is associated with haemosiderin accumulation, bronchial circulation angiogenesis (Williams et al. 2008), and fibrosis of the alveolar interstitium, bronchovascular bundle, septa, and pleura. During exercise, venous occlusion increases regional pulmonary capillary pressure, likely causing capillary rupture and resulting in bleeding (Deksen et al. 2009; Derksen et al. 2011).

\section{Clinical signs and lesions of exercise-induced pulmonary haemorrhage}

One of the clinical signs of EIPH is cough immediately after exercise, which is often due to the irritation caused by blood in contact with the cough receptors located in the 
lower area of the trachea (Pascoe 1997). Furthermore, many authors suggested that $1-5 \%$ of horses that exert inordinate effort suffer epistaxis (Pascoe 1997; Takahashi et al. 2001). The epistaxis may be bilateral and can occur up to $20 \mathrm{~h}$ after exercise in extreme cases. Epistaxis is more commonly observed in animals subjected to high-intensity sprints (Poole et al. 2007). The influence of EIPH on performance is variable; disabled horses and certain others are not affected, although EIPH is considered to have a real effect on performance in sport horses. Poor performance may ultimately be accompanied by exercise intolerance (Pascoe 1996; Ainsworth 2008). Those horses that have epistaxis during a race demonstrate a clear decrease in performance quality (Pascoe 1996). Thus, it is likely that the effect of this alteration on athletic performance is related to the volume of pulmonary haemorrhage (Derksen et al. 2011). It is possible, moreover, that a small amount of bleeding does not cause a significant decrease in performance. Furthermore, it is likely that the effects of bleeding are progressive and cumulative, leading ultimately to a significant decrease in performance quality. This may be because the blood in the lungs causes inflammation; erythrocytes are removed slowly and repeated exercise causes repeated episodes of EIPH (Pascoe 1997). At the same time, endoscopic studies have indicated no relationship between the final position of the horses in the race and the presence of EIPH (Hinchliff et al. 2005). The authors believed that performance problems should not be attributed to EIPH until all other potential causes of impaired performance have been ruled out (Pascoe 1997). Death from EIPH is rare and is caused primarily by pulmonary oedema induced by asphyxia (Cook 2002). Upon post mortem examination, the lesions manifest as bilateral symmetrical dark dorsal areas of the lung, discoloration of the subpleural arteries (bronchial arteries), bronchioles that are thickened with a mucous or gelatinous exudate, intense neovascularization of the bronchial artery, lung congestion (O'Callahan et al. 1987) and, in some cases, alveolar fibrosis (McKane and Slocombe 2002).

Diagnosis of exercise induced pulmonary haemorrhage

Use of a flexible endoscope and specific diagnostic methods to determine the presence of blood in the upper and lower airways of the horse has opened a vast field of research on the subject (Pascoe 1997). Blood endoscopic examination of the airways suggests EIPH; however, non-observance immediately after exercise does not rule out the presence of this disease (Sweeney 1991). For this reason, some authors suggest performing endoscopic observations 30 to $90 \mathrm{~min}$ post exercise, extending to the tracheal carina. Horses positive for EIPH are classified in grades from I to IV, depending on the amount and anatomic location of the blood found (Lapointe et al. 1994). Over the years, flexible endoscopy has been complemented by other diagnostic techniques such as X-rays, which allow for the identification of lobe pulmonary haemorrhage (Pascoe 1996, 1997). However, radiographic examination does not reveal bleeding lesions in certain horses (Sweeney 1991; Ainsworth 2004). The use of scintigraphic images facilitates better diagnosis of EIPH, with approximately $95 \%$ efficacy $\left(\mathrm{O}^{\prime} \mathrm{Ca}\right.$ llaghan et al. 1987). Studies of broncheoalveolar lavage (LBA) have indicated that there is an increase in the number of neutrophils, macrophages and haemosiderophages, which represent evidence of previous episodes of EIPH in horses with this disease (McKane et al. 1993; Doucet and Viel 2002). Finally ultrasonographic studies (Ferucci et al. 2009), electrocardiograms, and blood counts may be useful as adjuncts in the diagnosis of EIPH. However, although endoscopic diagnosis is considered to be the standard diagnostic method for this condition, the use of biomarkers that could aid in quantifying risk and the severity of the condition would represent an advance in equine sport medicine. Costa et al. (2011) demonstrated angiotensin-converting enzyme (ACE) activity increased in horses with a higher degree of haemorrhage. They used 
the setting of ACE activity in the plasma of racehorses as a promising biomarker for EIPH diagnosis.

\section{Treatment of exercise-induced pulmonary haemorrhage}

Although the EIPH was discovered several decades ago, no therapeutic regimen has been effective (Sweeney 1991; Harkins and Tobin 1995). The difficulty in obtaining an ideal treatment for EIPH is most likely due to the controversy regarding the mechanism of the pathology and the aetiology (Epp et al. 2006). These authors mentioned the demand that exists for prevention and treatment methods to control bleeding. Therefore, a series of manipulations and drug treatments have been researched and tested, but just few of them have demonstrated efficacy (Hinchcliff 2005). However, furosemide is the drug of choice in treating this condition (Hinchcliff et al. 2009). With respect to its mechanism of action, furosemide is known to block chloride reabsorption primarily and sodium reabsorption in the renal tubule secondarily; this increases the urine volume. Thus, reduction in the blood volume and relief of the right ventricular systolic function are necessary to overcome high atriopulmonary pressure. The attenuation of the increase in right atrial pressure and artriopulmonary pressure during exercise after furosemide administration may be due to the reduced volume of extracellular fluid and the release of E-type prostaglandin, which increase venous capacity (Manohar 1994). It has been shown that the administration of furosemide $4 \mathrm{~h}$ before each competition reduces the risk of EIPH (Pascoe 1997; Soma et al 2000). In addition, Goetz et al. (1999) showed that an additional dose of furosemide before the competition does not achieve a greater attenuation of pulmonary vascular pressure. The same authors concluded that this additional dose does not diminish the severity of the EIPH, compared to the use of a single dose. Soma et al. (2000) showed that the beneficial effects of furosemide decrease with age, as young horses have a better response to the drug compared to older individuals. According to Hinchcliff (2000), chronic administration of phenylbutazone impairs the positive effects of furosemide. This anti-inflammatory increases the pressure of the right ventricle and lungs, especially in the pulmonary capillaries. Soma and Ubho (1998) suggested that the negative effects of NSAIDs are due to the adverse reaction they have on the kidney, where furosemide acts. It was thought that the administration of clenbuterol decreased vascular resistance of the alveolar capillaries, but it has more recently been shown that the administration of clenbuterol for $11 \mathrm{~min}$ in individuals medicated with furosemide was ineffective in modifying the haemodynamic changes in the lungs. Clenbuterol increased the heart rate but did not decrease pulmonary vascular pressure (Manohar et al. 2000). In addition, in the horse, during inspiration, the upper airway generates $90 \%$ of the total resistance to airflow; $40-50 \%$ of this resistance is located in the nasal cavity, which becomes very important considering that the horse is a forced nasal breather (Erickson et al. 2001). For this reason, some authors have suggested that the use of nasal patches prevents the collapse of lateral nasal walls, which help keep the upper airway unobstructed for the passage of air and thus reduce the resistance of the upper airway to step air (Geor et al. 2001). The use of the patches reduces nasal airway resistance, but this reduction is insufficient to produce changes in physiological indicators, so its use does not diminish hypoxaemia, hypercapnia, lactic acid production or incidence of EIPH (Goetz et al. 2001). However, studies by Geor et al. (2001) in race horses showed that the simultaneous use of nasal patches and furosemide attenuated the presentation of EIPH and diminished the presence of erythrocytes in the BALF. In addition, Hinchcliff et al. (2005) suggested that EIPH is associated with impaired performance in thoroughbred racehorses that are not medicated with furosemide and do not use nasal dilator strips.

It would be interesting in future protocols to find treatments that achieve a significant reduction in vascular pressure in exercise horses. However, it is likely that the decrease 
in these indicators also reduces the ability to exercise; therefore, strategies aimed at achieving a significant decrease in pulmonary vascular pressure in horses to prevent EIPH are unlikely to be successful. Pulmonary haemorrhage is not dangerous in itself, but the blood in the tissue induces inflammatory responses, which could be the primary cause of the adverse effects observed in EIPH. Thus, it is reasonable to presume that therapeutic protocols designed to reduce the inflammation triggered by pulmonary haemorrhage will be the most successful.

\section{References}

Ainsworth D, Hackett R 2004: Disorders of the respiratory system. In: Reed SM, Bayly WM, Sellon DC (eds). Equine Internal Medicine. $2^{\text {nd }}$ ed. Saunders, Philadelphia, USA, pp 289-353

Ainsworth DM 2008: Lower airway function: responses to exercise and training. In: Equine exercise physiology: The Science of exercise in the athletic horse, Eds: KW Hinchcliff, RJ Goer and AJ Kaneps, Elsevier Saunders, New York, 193 p.

Araya O, Palma P, Salvi M, Bustamante H, Vits L 2005: Endoscopic determination of exercise-induced pulmonary haemorrhage in Chilean Criollo horses. Vet J 169: 311-313

Art T, Duvivier D, Votion D, Anciaux N, Vandenput S, Bayly W, Lekeux P 1998: Does an acute COPD crisis modify the cardiorespiratory and ventilatory adjustment to exercise in horses? J Applied Physiol 84: 845-852

Art T, Lekeux P 1994: Exercise induced pulmonary hemorrhage in horses: an enigma of equine medicine. Ann Méd Vét 138: 145-153

Bernard SL, Glenny RW, Erickson HH, Fedde MR. Polissar N, Basaraba RJ, Hlastala MP 1996: Minimal redistribution of pulmonary blood flow with exercise in racehorses. J Applied Physiol 81: 1062-1070

Birks EK, Shuler KM, Soma LR, Martin BB, Marconato L, Del Piero F, Teleis DC, Schar, D, Hessinger AE, Uboh CE 2002: EIPH: postrace endoscopic evaluation of standard breeds and thoroughbreds. Equine Vet J 34: $375-378$

Boucher J 1989: Exercise-induced echinocytosis. In: Jones WE, Equine sports medicine Philadelphia, Lea and Febiger, USA, pp 43-51

Caillaud C, Connes P, Bouix D, Mercier J 2002: Does haemorhelogy the paradox of hipoxemia during exercise in elite athletes or thoroughbred horses. Clin Hemorheol Microcirc 26: 175-181

Cook WR 2002: Bit-induced asphyxia in the horse: elevation and dorsal displacement of the soft palate at exercise. J Equine Vet Sci 22: 7-14

Cook WR, Williams R, Kirker-Head C 1988: Upper airway obstruction partial asphyxia as possible cause of exercise-induced pulmonary hemorrhage in the horse: An hypothesis. Equine Vet J 8: 11-26

Costa MF, Ronchi FA, Ivanow A, Carmona AK, Casarini D, Slocombe RF 2011: Association between circulating angiotensin-converting enzyme and exercise-induced pulmonary haemorrhage in thoroughbred racehorses. Res Vet Sci 93: 993-994

Derksen FJ, Slocombe RF, Gray PR, Robinson NE 1992: Exercise induced pulmonary hemorrage in horses with experimentally induced allergic lung disease. Am J Vet Res 53: 15-21

Derksen FJ, Williams KJ, Pannirselvam RR, de Feijter-Rupp H, Steel CM, Robinson NE 2009: Regional distribution of collagen and haemosiderin in the lungs of horses with exercise-induced pulmonary haemorrhage. Equine Vet J 41: 586-591

Derksen F, Williams K, Stack A 2011: Exercise-induced pulmonary hemorrhage in horses: the role of pulmonary veins. Compend Contin Educ Vet 33: E1-E6

Doucet M, Viel L 2002: Alveolar macrophages graded hemosiderin score from bronchoalveolar lavage in horses with exercise induced pulmonary hemorrhage and controls. J Vet Intern Med 16: 281-286

Erickson HH 1992: Pulmonary artery and aortic pressure changes during high intensity treadmill exercise in the horse: effect of furosemide and phentolamine. Equine Vet J 23: 434-437

Erickson HH, Bernard SL, Glenny RW, Fedde MR, Polissar NL, Basaraba RJ, Walther SM, Gaughan EM, McMurphy R, Hlastala MP 1999: Effect of furosamide on pulmonary blood flow distribution in resting and exercising horses. J Applied Physiol 86: 2034-2043

Epp TS, McDonough P, Padilla DJ, Gentile JM, Edwards KL, Erickson HH, Poole DC 2006: Exercise-induced pulmonary haemorrhage during submaximal exercise. Equine Vet J Supplement 36: 502-507

Erickson HH, Hildreth T, Poole DC, Cox J 2001: Management of exercise induced pulmonary hemorrhage in non racing performance horses. Compend Contin Educ Vet 23: 1090-1093

Fedde M, Wood S 1993: Rheological characteristics of horse blood: significance during exercise. Respir Physiol 94: $323-335$

Geor RJ, Ommundson L, Fenton G, Pagan JD 2001: Effects of an external nasal strips and furosemide on pulmonary hemorrhage in thoroughbreds following high-intensity exercise. Equine Vet J 33: 537-539

Goetz TE, Manohar M, Hassan AS, Baker GJ 2001: Nasal strips do not affect pulmonary gas exchange anaerobic metabolism, or EIPH in exercising thoroughbreds. J Applied Physiol 91: 2378-2385 
Goetz TE, Manohar M, Magid JH 1999: Repeated administration of furosemide dose not offer an advantage over single dosing in attenuating exercise-induced pulmonary hypertension in thoroughbred horses. Equine Vet $\mathrm{J}$ 30: $539-545$

Harkins JD, Mundy G, Stanley S, Harrinson L, Poonacha K, Williams N, Tobin T 1997: Exercise-induced pulmonary hemorrhage: review of etiology and pathogenesis. Vet Clin North Am Equine Pract 19: 22-28

Harkins JD, Tobin T 1995: Racing horses, nitroglycerin and exercise induced pulmonary hemorrhage. Equine Vet J 27: 240-241

Hinchcliff KW 2000: Counting red cells- is it an answer to EIPH. Equine Vet J 32: 979-984

Hinchcliff KW, Jackson MA, Morley PS, Brown JA, Dredge AE, O'Callaghan PA, McCaffrey JP, Slocombe RE, Clarke AE 2005: Association between exercise-induced pulmonary hemorrhage and performance in thoroughbred racehorses. J Am Vet Med Assoc 227: 768-774

Hinchcliff KW, Morley PS, Guthrie AJ 2009: Efficacy of furosemide for prevention of exercise-induced pulmonary hemorrhage in thoroughbred racehorses. J Am Vet Med Assoc 235: 76-82

Hinchcliff KW, Morley PS, Jackson MA, Brown JA, Dredge AF, O'Callaghan, PA, McCaffrey JP, Slocombe RF, Clarke AF 2010: Risk factors for exercise-induced pulmonary haemorrhage in thoroughbred racehorses. Equine Vet J supplement 38: 228-234

Langsetmo I, Meyer MR, Erickson HH 2000: Relationship of pulmonary arterial pressure to pulmonary hemorrhage in exercise horses. Equine Vet J 32: 379-384

Langsetmo I, Weigle GE, Erickson HH, Fedde MR 1999: Influence of furosamide on dynamic cardiac variables during exercise. Equine Vet J 30: 170-173

Lapointe JM, Vrins A, McCarvill E 1994: A survey of exercise-induced pulmonary hemorrhage in Quebec standard breeds racehorses. Equine Vet J 6: 482-485

Markham G 1688: Markham's master-piece revived: Containing all knowledge belonging to the Smith, FUFFieF of horse-leach. London: John Richardson for Tho. Passinger. p. 184

McKane SA, Canfield PJ, Rose RJ 1993: Equine bronchoalveolar lavage cytology: survey of thoroughbred racehorse in training. Australian Vet J 70: 401-404

McKane SA, Slocombe RF 2002: Alveolar fibrosis and changes in equine lung morphometry in response to intrapulmonary blood. Equine Vet J supplement 34: 451-458

Manohar M 1994: Pulmonary vascular pressures of thorougbreds increase rapidly and to higher level with rapid onset of high-intensity exercise than slow onset. Equine Vet J 26: 496-499

Manohar M, Goetz TE, Hassan AS 2001: Effect of prior high-intensity exercise on exercise-induced arterial hypoxemia in thoroughbred horses. J Applied Physiol 90: 2371-2377

Manohar M, Goetz TE, Rothenbaum P, Humphrey S 2000: Clenbuterol administration does not enhance the efficacy of furosemide in attenuating the exercise-induced pulmonary capillary hypertension in thoroughbred horses. J Vet Pharmacol Ther 23: 389-395

Manohar M, Hutchens E, Coney E 1993: Pulmonary hemodynamics in the exercising horses and their relationship to exercise-induce pulmonary hemorrhage. Br Vet J 149: 419-428

Michelotto PV Jr, Muehlmann LA, Zanatta AL, Bieberbach EW, Kryczyk M, Fernandes LC, Nishiyama A 2011: Pulmonary inflammation due to exercise-induced pulmonary haemorrhage in thoroughbred colts during race training. Vet J 190: e3-6

Moran G, Carrillo R, Campos B, Garcia C 2003: Endoscopic evaluation of exercise induced pulmonary hemorrhage in polo ponies. Arch Med Vet 35: 109-113

Newton JR, Rogers K, Marlin DJ, Wood JL, Williams RB 2005: Risk factors for epistaxis on British racecourses: evidence for locomotory impact-induced trauma contributing to the aetiology of exercise-induced pulmonary haemorrhage. Equine Vet J 37: 402-411

Newton J, Wood J 2002: Evidence of an association between inflammatory airway disease and EIPH in young thoroughbreds during training. Equine Vet J 34: 417-424

O’Callaghan MW, Hornof WJ, Fisher PE, Pascoe JR 1987: Exercise-induced pulmonary hemorrhage in the horse: results of a detailed clinical, post mortem and imaging study. VII. Ventilation/perfusion scintigraphy in horses with EIPH. Equine Vet J 19: 423-427

Oikawa M 1999: Exercise induced hemorrhage lesions in the dorsocaudal extremities of the caudal lobes of the lungs of young thoroughbred horses. J Comp Pathol 121: 339-347

Pascoe JR 1996: Exercise-induced pulmonary hemorrhage: unifying concept. In Proceeding. 42nd Annual American Association of Equine Practitioner Convention, p 220-226

Pascoe JR 1997: Exercise-induced pulmonar. In: Robinson NE. Current therapy in equine medicine. 4nd ed. Saunders, Philadelphia, USA, p 441-443

Pascoe JR, McCabe AE, Franti CE, Arthur RM 1981: Efficacy of furosemide in the treatment of exercise-induced pulmonary hemorrhage in thoroughbred racehorses. Am J Vet Res 42: 703-707

Poole DC, Epp TS, Erickson HH 2007: Exercise-induced pulmonary haemorrhage (EIPH): mechanistic bases and therapeutic interventions. Equine Vet J 39: 292-293

Robertson JB 1913: The heredity of blood-vessel breaking in the thoroughbred. Bloodstock Breeders' Rev 2: 265-281

Schroter RC, Leeming A, Denny E, Bharath A Marlin DJ 1999: Modelling impact-initiated wave transmission 
through lung parenchyma in relation to the etiology of exercise-induced pulmonary hemorrhage. Equine Vet $\mathrm{J}$ Supplement 30: 34-38

Shroter RC, Marlin DJ, Denny E 1998: Exercise induced hemorrhage pulmonary (EIPH) in horses results from locomotory impact induced trauma novel, unifying concept. Equine Vet J 30: 186-192

Soma LR, Birks EK, Uboh CE, May L, Teleis D, Martini J 2000: The effects of furosemide on racing time of Standardbred pacers. Equine Vet J 32: 334-340

Soma LR, Uboh CE 1998: Review of furosemide in horses racing: its effects and regulation. J Vet Pharmacol Ther 21: 228-240

Sweeney C 1991: Exercise-induced pulmonary hemorrhage. Vet Clin North Am Equine Pract 7: 93-104

Takahashi T, Hiraga A, Ohmura H, Kai M, Jones JH 2001: Frequency of and risk factors for epistaxis associated with exercise induced pulmonary hemorrhage in horse. J Am Vet Med Assoc 218: 1462-1464

West JB, Mathieu-Costello O 1994: Stress failure of pulmonary capillaries as a mechanism for exercise induced pulmonary hemorrhage in the horse. Equine Vet J 26: 441-447

West JB, Mathieu-Costello O 1995: Stress failure of pulmonary capillaries as limiting factor for maximal exercise. Eur J Appl Physiol 70: 99-108

West JB, Mathieu-Costello O 1998: Stress-induced injury of pulmonary capillaries. Proc Assoc Am Physicians 110: 506-512

West JB, Mathieu-Costello O, Jones JH, Birks EK, Logemann RB, Pascoe JR, Tyler WS 1993: Stress failure of pulmonary capillaries in racehorses with exercise-induced pulmonary hemorrhage. J Applied Physiol $\mathbf{7 5}$ : 1097-109

Weiss DJ, Geor RJ, Smith CM Jr 1994: Effects of echinocytosis on hemorrheologic values and exercise performance in horses. Am J Vet Res 55: 204-210

Weiss DJ, Smith CM Jr 1998: Haemorrheogical alterations associated with competitive racing activity in horses: implications for exercise-induce pulmonary hemorrhage (EIPH). Equine Vet J 30: 7-12

Williams KJ, Derksen FJ, de Feijter-Rupp H, Pannirselvam RR, Steel CM, Robinson, NE 2008: Regional pulmonary veno-occlusion: a newly identified lesion of equine exercise-induced pulmonary hemorrhage. Vet Pathol 45: 316-326 